\title{
Foraminifera-bound nitrogen isotopes: From mechanistic understanding to a case study in the equatorial Pacific
}

HAOJIA REN ${ }^{1}$, YI-CHI CHEN ${ }^{1}$, WEI-NING FANG ${ }^{1}$, ANJA

STUDER $^{2}$, JIMIN YU ${ }^{3}$, ALFREDO MARTÍNEZ-GARCÍA ${ }^{4}$, GERALD H. HAUG ${ }^{4}$,HOWARD J. SPERO ${ }^{5}$, DANIEL M. SIGMAN $^{6}$

${ }^{1}$ Dept. of Geosciences, National Taiwan University, Taiwan, abbyren@ntu.edu.tw

${ }^{2}$ Dept. of Environmental Sciences, University of Basel, Switzerland

${ }^{3}$ Research School of Earth Sciences, The Australian National University, Australia

${ }^{4}$ Climate Geochemistry Dept., Max Planck Institute for Chemistry, Germany

${ }^{5}$ Earth and Planetary Sciences, University of California Davis, U.S.A.

${ }^{6}$ Dept. of Geosciences, Princeton University, U.S.A.

The isotopic composition of organic nitrogen preserved within planktonic foraminifera shells $\left(\mathrm{FB}-\delta^{15} \mathrm{~N}\right)$ is emerging as a paleoceanographic proxy for studying the history of the marine nitrogen cycle. Heterotrophic organisms are typically elevated in $\delta^{15} \mathrm{~N}$ relative to their food, due to preferential excretion of ${ }^{14} \mathrm{~N}$-ammonium. We report culture experiments showing that $\mathrm{FB}-\delta^{15} \mathrm{~N}$ of dinoflagellate symbiont-bearing foraminifera species do not exhibit this "trophic enrichment", due to efficient nitrogen recycling between the symbionts and the foraminifera host. These results help to improve our understanding of how the $\delta^{15} \mathrm{~N}$ of nitrate consumed in surface waters is reflected in $\mathrm{FB}-\delta^{15} \mathrm{~N}$. Applying this proxy, we reconstruct deglacial $\mathrm{FB}-\delta^{15} \mathrm{~N}$ changes in records across the equatorial Pacific. Bulk sediment $\delta^{15} \mathrm{~N}$ records in this region show lower ice age $\delta^{15} \mathrm{~N}$, which has been interpreted to reflect weaker water column denitrification in the eastern Pacific. In contrast, the $\mathrm{FB}-\delta^{15} \mathrm{~N}$ records show no ice age-to-Holocene $\delta^{15} \mathrm{~N}$ difference, suggesting that the inferred glacial reduction in eastern Pacific water column denitrification may be overestimated. In addition, all $\mathrm{FB}-\delta^{15} \mathrm{~N}$ records show a deglacial maximum. This may reflect a transient $\delta^{15} \mathrm{~N}$ maximum in thermocline nitrate due to the deglacial change in Southern Ocean surface nitrate consumption and/or an increase in water column denitrification. The eastern Equatorial Pacific has a weaker deglacial peak in $\delta^{15} \mathrm{~N}$ relative to the western Equatorial Pacific. This is best explained by enhanced upwelling in the eastern Equatorial Pacific during the deglaciation. 